Vol. 8, Issue 12, December 2021

DOI: 10.17148/IARJSET.2021.81215

\title{
Development of a Software for the Basic Learning of the Mayan Language
}

\author{
Victor M. Chi Pech ${ }^{1}$, Lizzie E. Narváez Díaz ${ }^{2}$, Erika R. Llanes Castro³ \\ Faculty of Mathematics, Autonomous University of Yucatán, Mérida, Yucatán, México ${ }^{1-3}$
}

\begin{abstract}
This work presents the development of a software used as a tool for the basic learning of the Mayan language through a game, which will be used in the first instance in elementary schools in the east of the state of Yucatán, Mexico, in order to continue preserving the Mayan culture and therefore the Mayan language, specifically the dialect that characterizes the Yucatecans. The achievement of communication through languages is of great importance since human beings today could not understand life without the ability to access the information that is being generated at all times in all areas. The software interface that is presented to the user is friendly and intuitive so that the user can learn to use it without any problem.
\end{abstract}

Keywords: Software, educational software, teaching-learning process, educational game, mayan language.

\section{INTRODUCTION}

Nowadays, technological advances are highly related to all areas of knowledge and, therefore, of society; being the computer one of the main tools used to allow communication and information management through different software. Some schools promote interactive teaching, with the clear intention that this will lead to improvements in student learning. Technical and pedagogical interactivity points a way towards a greater focus on learning objectives during the activities carried out in classrooms, in order to enable students to be more autonomous in exploiting the possibilities of information and communication technologies [1]. To support the teaching-learning process, computer programs called educational software are developed [2] and are often used in educational institutions to support teachers in the teachinglearning process.

Educational software was born in the 1960s but had a greater impact in the 1980s. The first steps of educational software in didactic matters were taken by the Logo language developed by the Massachusetts Institute of Technology, which was used in schools and universities [3].

The human being today could not understand life without the ability to access the information that is being generated at all times in all areas, and oral communication is the most common form that allows human beings to participate in all environments of society, however, communication in the Mayan language is something that is currently being lost. Because technology has constantly influenced daily lives of people, developing educational software that has the potential to go hand in hand with culture is very useful.

In order to contribute to the increase of people who make use of the Mayan language, specifically with the dialect spoken in the Yucatán Peninsula, it was decided to develop a software at the Tizimín Multidisciplinary Unit of the Autonomous University of Yucatán, located in Tizimín, Yucatán, México, that enables people to learn vocabulary of this language in a playful way. The software was developed in the Visual Basic programming language and will initially be used in primary schools in the eastern part of the state of Yucatán, specifically in the city of Tizimín, located 160 kilometers from the state capital.

This software will help primary school children to get closer to the Mayan language at their school by means of a computer software that is interactive and entertaining.

\section{EDUCATIONAL SOFTWARE}

Educational software refers to computer programs made with the purpose of being used as facilitators of the process of teaching and consequently of the learning one, with particular features such as ease of use, the fact that it is interactive, and the possibility of personalizing the learning speed of students [4].

One of the characteristics of educational software is to be interactive [5], since it is based on multimedia and/or animations that allow children and young people to feedback what they have learned in classes through exercises and games.

Sánchez indicates that the literature defines the generic concept of educational software as any computer program whose structural and functional characteristics support the process of teaching, learning, and administering. Educational 


\section{International Advanced Research Journal in Science, Engineering and Technology}

Vol. 8, Issue 12, December 2021

\section{DOI: $10.17148 /$ IARJSET.2021.81215}

software is more narrowly defined as learning material designed to be used on a computer in the teaching and learning process [6].

\section{MAYAN LANGUAGE}

The Mayan language is one of the most widely spoken languages in Mexico, according to the National Institute of Statistics and Geography [7], however, despite this, it is also a language at risk, since fewer and fewer Mayan speakers make use of it. The cause of this is that Mayan has ceased to be passed down as a mother tongue. [8], the older people of towns no longer exercise this teaching to the following generations and that is why the Mayan speakers are being reduced in number.

In the words of Gabriela Tec Chan, "When a language is lost, when a word is forgotten, then an important part of a culture is lost" [8], and according to her, with the passage of time, in the absence of the practice or of transmitting this language to Yucatecan children and youth, there are fewer and fewer Mayan speakers in the state.

The struggle for the survival of the Mayan language is arduous because discriminatory practices persist and its diffusion in the written and electronic media is almost non-existent. It should be noted that in many communities in the interior of the state of Yucatan, the Mayan language is used on a daily basis, but is only spoken by adults [9].

However, thanks to the technological revolution, systems, applications, virtual courses, among others, have emerged that fight against the loss of the Mayan culture and its language, such as Aprendiendo Maya Jugando [10] and Aprende Maya - Curso y Diccionario Maya [11], and the software described here whose objective is related to the learning of the Mayan language.

As pointed out in [9], we should not lament the low use of the Mayan language, but rather campaign in favor of the language that our ancestors inherited us. It is necessary to join forces so that the Mayan language remains alive, and this is one of the reasons why it was decided to develop the Kaxan Núup software.

\section{DESIGN OF THE SOFTWARE}

For the development of the software, the interface, the buttons, as well as the visual objects implemented in it were first designed. Subsequently, the behavior of the interface and of each of its scenarios and visual objects was defined in the Visual Basic programming language. In each scenario a series of attractive visual objects were implemented, always keeping in mind to be a support in the learning process of the Mayan language.

\section{RESULTS}

As a result of this work, the software to learn the Mayan language was obtained, which has the form of a memory game called Kaxan Núup, which has a didactic approach that consists of learning words by matching pairs of cards and advancing to more cards, through the selection of buttons identified as easy, intermediate and difficult.

To start with the execution of this software program, the user must click on the icon of the program. Then, the main window will be displayed, where the user is shown the name of the software and the play button to start it, as shown in figure 1 .

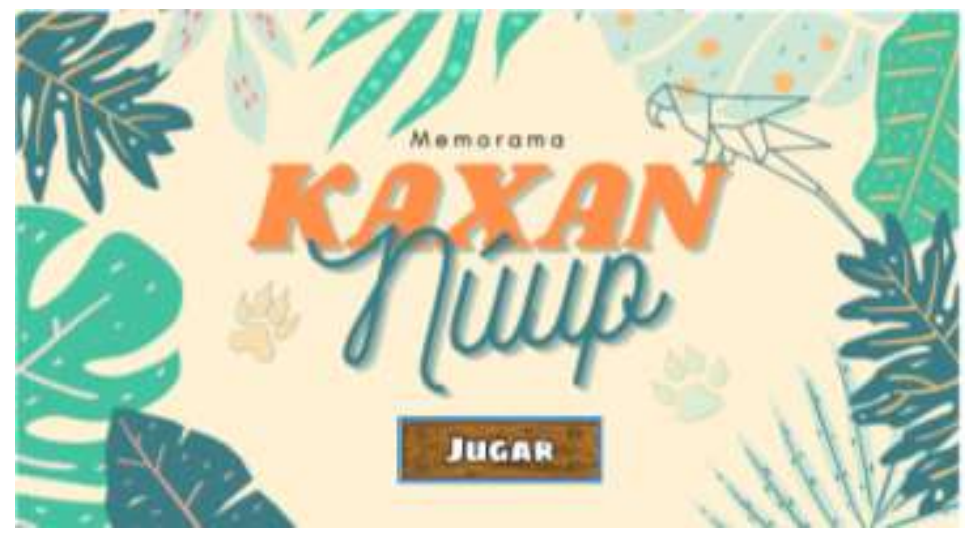

Fig. 1 Main window of the software

By clicking on the play button, users will be shown a window called menu in which they can select the difficulty level of the memory game by choosing between three levels: easy, intermediate or difficult, as shown in figure 2 . The selection of the option labelled as easy will allow the player to have a memory game of six pairs of cards, the option 


\section{DOI: 10.17148/IARJSET.2021.81215}

labelled as intermediate will allow to have a memory game of nine pairs of cards and the option labeled as difficult will allow the player to have twelve pairs of cards.

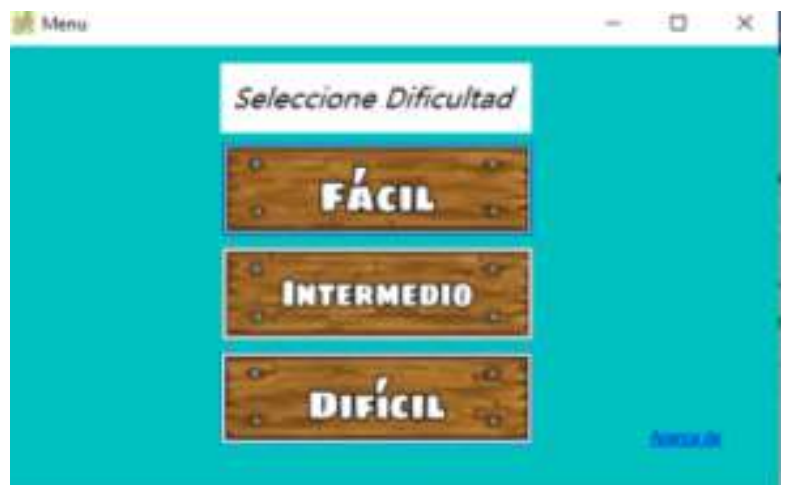

Fig. 2 Window to select the difficulty level of the game

In this first stage of software development, the cards consist of the image of an object with its respective name in the Mayan language, and its corresponding pair consists of the same image of the object but with its respective name in Spanish.

Once the game difficulty level has been selected and the corresponding button has been clicked, a window with the following characteristics will be displayed (see figure 3):

a) a title bar containing the word that will identify the difficulty level of the game, as well as the button to minimize, maximize and close the window (which leads to the menu window);

b) a work area that contains the number of cards according to the difficulty level of the game and a box that will provide information related to the time it takes the player to complete the game.

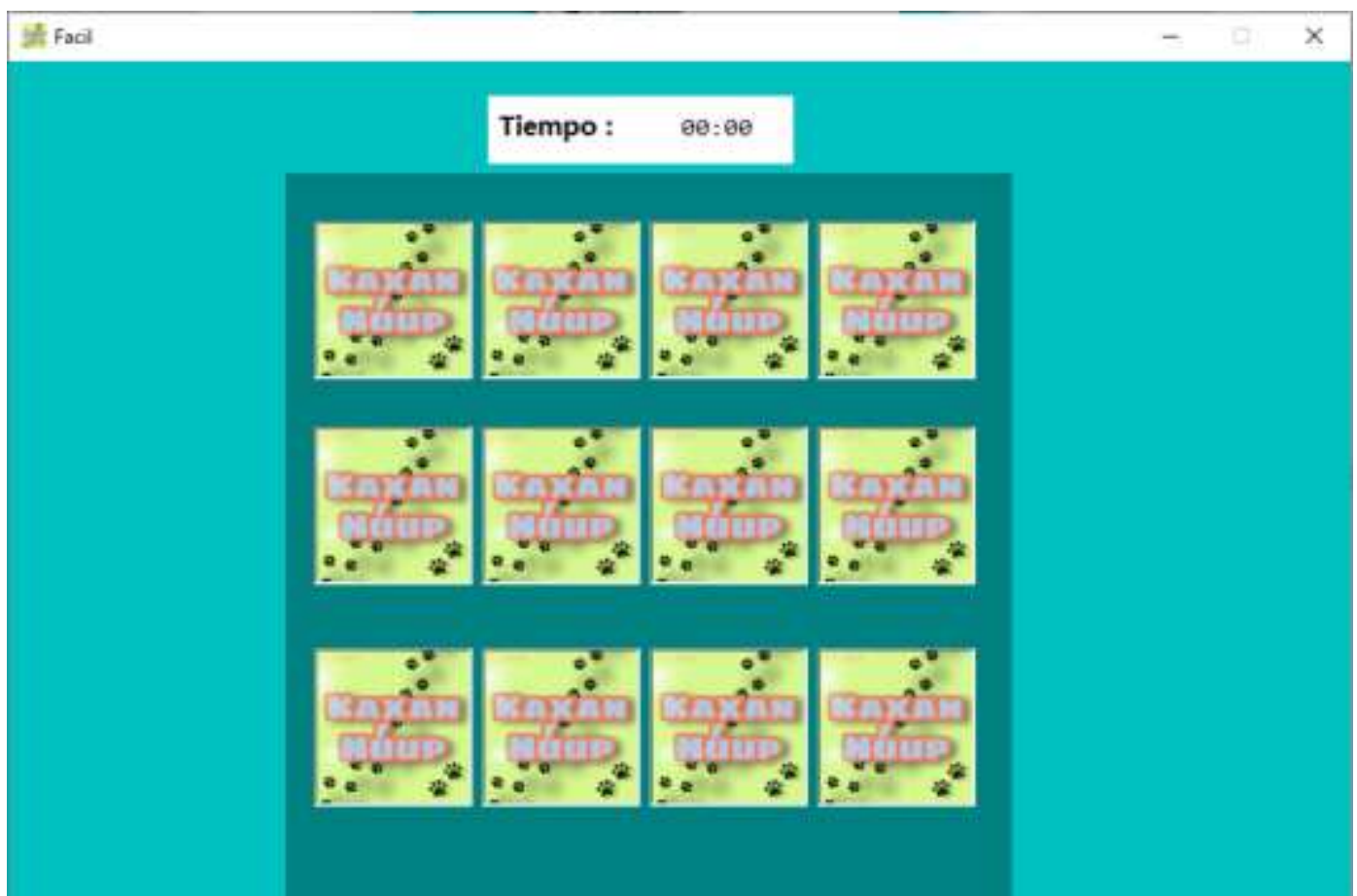

Fig. 3 Window corresponding to the memory game with an easy level of difficulty

At the beginning all the cards contain the name of the game called Kaxan Núup, as shown in figure 3. As in many card matching games, the user must select two cards, one of which is expected to show the image of an object with its corresponding name in the Mayan language, and the other one to show the same image of the object but with its corresponding name in Spanish. If the cards selected by the user are a pair of equivalent cards, then the cards will 


\section{International Advanced Research Journal in Science, Engineering and Technology}

Vol. 8, Issue 12, December 2021

\section{DOI: 10.17148/IARJSET.2021.81215}

remain visible with the image of the object and its corresponding name in Mayan language and in Spanish. In case of not matching, the cards will return to their original state showing again the name of the game.

Once the game is over, the user will observe through a window the time invested in the game as well as a question to find out if he/she wants to play again, as shown in figure 4.

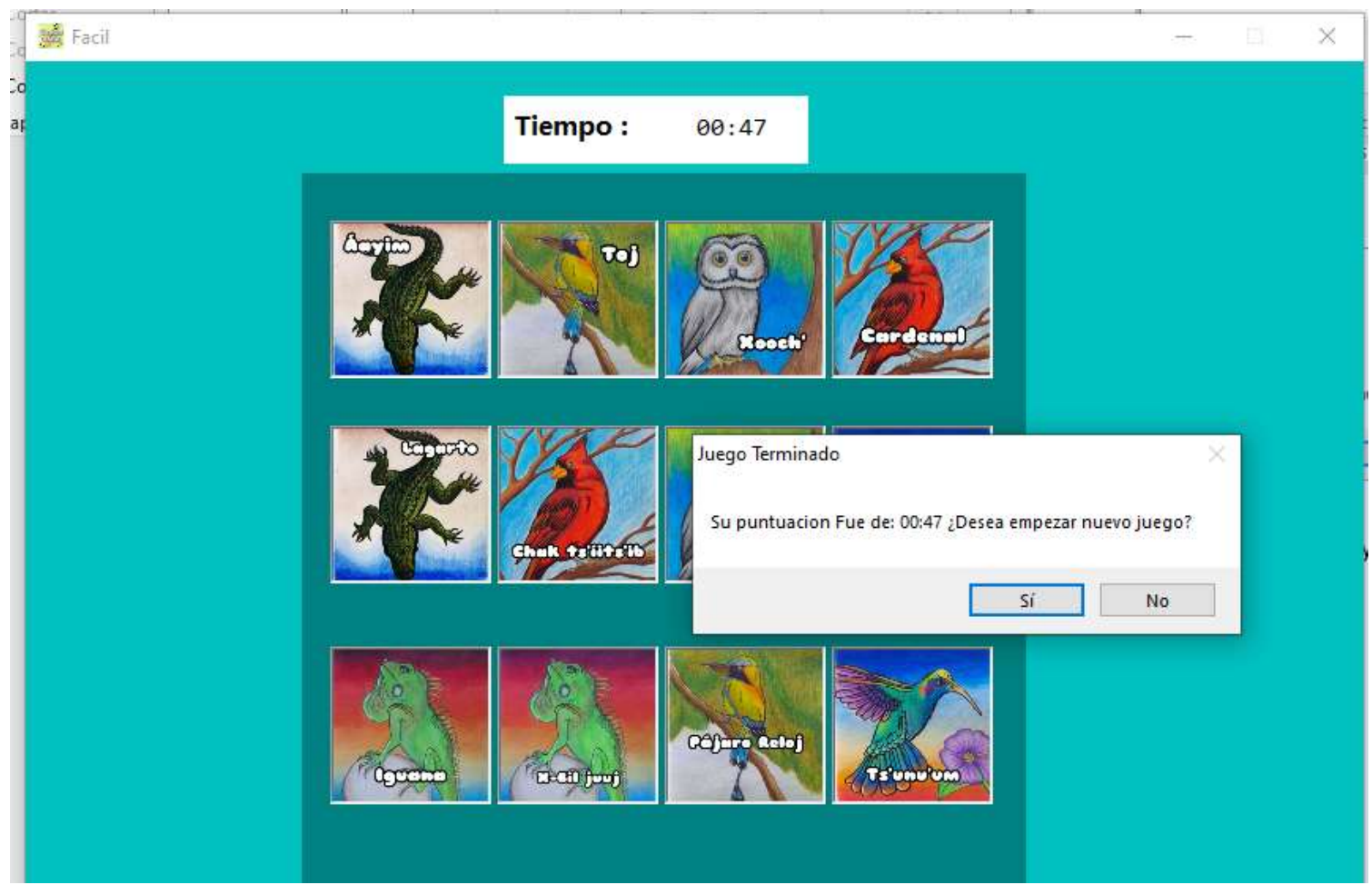

Fig. 4 Window with game completion time

If the user chooses to play again, then the cards will be presented again according to the previously selected difficulty level, but being presented randomly, that is, it will contain other object images. In case the user wants to play again but with another level of difficulty, it is necessary to click the close button of the active window to return to the menu window.

\section{EXPERIMENTS}

Tests were carried out with a total of 20 people, who were selected only because they were close to the home of the software developers. There was no process to determine the inclusion of participants in the test due to the health situation that is currently being experienced worldwide.

The next step was to introduce them to the software, providing them with instructions on how to use it. They then proceeded to make use of the software, to finally provide their opinion regarding the software, of which they commented that the game was very entertaining, it was not complicated to use, they learned in a fun way how to write the name of some objects in the Mayan language, they felt very happy to learn how the name of some objects of daily use are written in the Mayan language since this would allow them to communicate even using these basic concepts with other people who speak this language, and as for the figures and colors of the windows it was very striking. Some users commented that it would be interesting to add more pairs of cards to the game in order to increase the complexity of the memory game.

Some users commented that the memory game for learning basic words in the Mayan language could be used not only by children but by anyone interested in learning the Mayan language in a basic way. During the execution of the tests, it was observed that some users tried to pronounce the name of the displayed objects in the Mayan language. 


\section{International Advanced Research Journal in Science, Engineering and Technology}

Vol. 8, Issue 12, December 2021

DOI: $10.17148 /$ IARJSET.2021.81215

\section{CONCLUSIONS}

Promoting the Mayan language in our society is of great importance to continue preserving it, and what better way to do it than in a way that is enjoyable and entertaining? The software presented here provides an alternative to achieve the above described and allowed users to learn some basic words of this language making more people interested in its conservation.

The software developed, called Kaxan Núup, had a friendly and attractive interface to facilitate the learning of the name of some objects in the Mayan language. The software was tested by 20 people who provided favorable feedback on the graphical interface, although it is important to mention that it has not yet been tested on a large scale and in classroom environments, which is necessary to get feedback from the intended users, mainly children of primary school age.

Kaxan Núup is a tool that can be used to assist the learning process in educational institutions where the Mayan language is taught by facilitating learning by students and teaching by teachers. Likewise, it can serve as a support in schools that do not teach the Mayan language in order to motivate their students to become interested in the Mayan culture.

\section{ACKNOWLEDGEMENTS}

We thank the students of the fourth semester of the Bachelor of Software Engineering of the Multidisciplinary Unit Tizimín who took the Theory of Programming Languages course in the semester January - May 2021 for designing the images presented here.

\section{REFERENCES}

[1] Kennewell S., Tanner H., Jones S., \& Beauchamp G. Analysing the use of interactive technology to implement interactive teaching. Journal of Computer Assisted Learning, vol. 24, pp. 61-73, 2008.

[2] R. P. Lourdes, D. L. Junior, G. M. Xaily, y F. C. Caridad, “Software educativo, hipermedia o entorno educativo?”, Acimed. Vol. 18, No. 4, pp. $1-11,2008$.

[3] C. Zulma. Una metodología para el diseño, desarrollo y evaluación de Software Educativo. MAO, Tésis. Facultad de Informática, Universidad Nacional de La Plata, La Plata, Buenos Aires, Argentina, 2000. [Consultado: 21/10/2021] Disponible en: http://sedici.unlp.edu.ar/handle/10915/4055

[4] Vélez, C.; Estrategias de enseñanza con uso de las tecnologías de la información y comunicación para favorecer el aprendizaje significativo. Tecnológico de Monterrey, Escuela de Graduados en Educación, 2012, Colombia.

[5] R. F. Matilde. Metodologías para el Desarrollo de Software Educativo. LSC monografía, Instituto de Ciencias Básicas e Ingeniería, Centro de Investigaciones en Tecnologías de Información y Sistemas, Universidad Autónoma del Estado de Hidalgo, Pachuca de Soto Hgo, México, 2007, Disponible en: https://www.academia.edu/16334567/Metodologias_software_educativo

[6] Sánchez, J.; Nuevas Tecnologías de la Información y Comunicación para la Construcción del Aprender. Editorial Universitaria, 2000, Chile.

[7] México en Cifras, Yucatán, INEGI, Recuperado de http://www.beta.inegi.org.mx/app/areasgeograficas/?ag=31\#tabMCcollapse-Indicadores

[8] Notimex, "Maya dejó de transmitirse como lengua materna, alerta experta", El Diario, Mérida, Yucatán, 2014, Disponible en: http://diario.mx/Nacional/2014-02-23_7a18693c/maya-dejo-de-transmitirse-como-lenguamaterna-alerta-experta/

[9] Martín Hu Macedonio. La maya, lengua viva y maravillosa. Diario de Yucatán, febrero, 2019. Disponible en https://www.yucatan.com.mx/editorial/la-maya-lengua-viva-y-maravillosa

[10] A. P. Rudiel, H. S. Nahim, P. Luis A., y C. H. José M., "Aprendiendo Maya Jugando”. Naruma Solution. Disponible en: Google Play Store

[11] C. M. Vicente, "Aprende Maya-Curso y Diccionario Maya", Secretaría de Educación Yucatán. 